\title{
MRS Workshop Series Presents High- $\kappa$ Gate Dielectrics and Transparent Conducting Oxides
}

The Materials Research Society has established the MRS Workshop Series, which deal with highly focused and compelling subjects, as do the MRS Fall and Spring Meeting symposia. However, Workshops differ significantly in that they - allow attendees to focus their full attention to a designated topic over a 2-3-day period;

- offer much more interaction and discussion between speakers and the audience;

- limit the size of the audiences to promote interaction; and

- offer attendees a more in-depth review of important topics than is typically allowed in a "snapshot" symposium.

The Workshop schedule consists of presentations by acknowledged experts, while also allowing for selected solicited talks and posters.

\section{High- $\kappa$ Gate Dielectrics}

The first Workshop presented this year is High-к Gate Dielectrics, June 1-2, in New Orleans, LA. The Workshop Chair is Glen Wilk (Lucent Technologies) and the coorganizers are Veena Misra (North Carolina State University) and Eric Vogel (National Institute of Standards and Technology). The scaling of the gate oxide in complementary metal oxide semiconductor (CMOS) technology has rapidly accelerated over the past several years. This rate of scaling is manifested by the 1999 ITRS (International Technology Roadmap for Semiconductors) timeline, which now calls for an $\mathrm{SiO}_{2}$ gate oxide thickness less than $2.0 \mathrm{~nm}$ for sub-0.13 $\mu \mathrm{m}$ technology nodes. This extremely aggressive march toward ultrathin oxide layers has placed a very high priority on finding a high- $\kappa$ replacement for $\mathrm{SiO}_{2}$ that will allow CMOS scaling to continue at this remarkable pace.
This MRS workshop will span two days of invited presentations to create a focused meeting on the topic of high- $\kappa$ gate dielectrics. It is intended to bring together leading researchers in this field for discussion on the critical issues which must be addressed and solved in order for high- $\kappa$ materials to successfully replace $\mathrm{SiO}_{2}$. Along these lines, only minimal discussion will take place on issues related to ultrathin $\mathrm{SiO}_{2}$. The critical issues will include interface stability, physical and electrical analysis, and CMOS process integration compatibility.

To permit in-depth discussion, invited presentations will be 30-45 minutes, with appropriate time for questions. Two panel discussions will address the key roadblocks facing high- $\kappa$ gate dielectrics. Representatives from major tool vendors will be present at the Workshop and in the panel discussions, as their input will be essential for understanding the requirements of process capability and tool development timelines. This Workshop will set the course for the integration of high- $\kappa$ gate dielectrics into CMOS technology.

\section{Transparent Conducting Oxides}

The second Workshop in the series is Transparent Conducting Oxides, to be held June 19-20, in Denver, CO. The coorganizers of the Workshop are David Ginley and Timothy Coutts of NREL and the co-organizers are Tom Mason (Northwestern University) and Clark Bright (Delta V Technologies). Transparent conducting oxides (TCOs) are vital thin-film components in several potentially largevolume applications such as photovoltaic modules, flat-panel displays, and architectural coatings. Although TCO coatings were not initially a performance-limiting factor for these applications, the indications are that in next-generation of these and other high performance applications, they may well be. The purpose of the Workshop is to bring together a critical mass of representatives from industry, the national laboratories, and universities to discuss prospects, needs, challenges and opportunities for TCOs. The expected outcome is the formation of a coordinated effort of research and development for improved and new TCOs by developing synergies between the various sectors represented.

Keynote addresses will be made on the following critical topics in order to develop a perspective on the current challenges and opportunities in the TCO field:

- large area deposition,

- commercialization problems/issues,

- new TCO materials,

- fundamental TCO research, and

- novel applications.

Attendees will participate in working group discussions based on the topical areas. Each group will focus on the key aspects of that topic, particularly the problems, opportunities, and resources required to achieve success.

The proceedings of the Workshop will be published which will present both a summary as to the state of the TCO field and a picture of the needs and opportunities in the area. The cost of the proceedings volume will be covered in the registration fees for the workshop.

For more information, contact the Materials Research Society, MRS Workshop Series, 506 Keystone Drive, Warrendale, PA 15086; tel. 724-779-3003; fax 724779-8313; e-mail info@mrs.org. Watch MRS Bulletin or the MRS website (www.mrs. org) for details on future Workshops. M[R]S
WWW.

mrs.

org/

meetings/

\section{VISIT THE MRS WEBSITE FOR MEETING INFORMATION}

- 2000 MRS Fall Meeting

Technical Symposia

-2000 MRS Spring Meeting

Program

- MRS Workshop Series

Information about MRS Workshops including the two MRS Workshops held in 1999, as well as Extended Abstracts for the 1999 Workshop on Tribology.
- Upcoming MRS Meetings

Looking ahead to future MRS meetings

- Previous MRS Meetings

Archived information on previous MRS Meetings highlights, abstracts, programs and more

\section{- Other Materials-Related Meetings}

Compilation of upcoming meetings of relevance to materials researchers, including MRS co-sponsored Meetings

www.mrs.org/meetings/ 


\section{MRS Invites No inations for the Von Hippel Award, Tumbull Lectureship, and MRS Medal}

The Materials Research Society is seeking nominations for the Von Hippel Award, the Turnbull Lectureship, and the MRS Medal. The deadline for nominations is June 1, 2000. These awards will be presented at the 2000 MRS Fall Meeting, November 27-December 1, in Boston.

The MRS Awards Program recognizes outstanding contributors to the progress of materials research. Nomination forms and details about eligibility and nomination criteria are available from Sue Novosel, Materials Research Society, 506 Keystone Drive, Warrendale, PA 15086-7573; phone 724-779-3004 ext. 102; fax 724-779-8313. Further information about each award can also be obtained from the MRS website at www.mrs.org.

\section{Von Hippel Award Acknowledges Outstanding Interdisciplinary Work in Materials Research \\ The Von Hippel Award, first presented to Arthur R. von Hippel whose interdisci-}

plinary and pioneering research typified the spirit of the award, is the Materials Research Society's highest honor. The recipient is recognized for brilliance and originality combined with vision that transcends the boundaries of conventional scientific disciplines. The Award includes a $\$ 10,000$ cash prize, honorary membership in MRS, and a unique trophy-a mounted ruby laser crystal symbolizing the manyfaceted nature of materials research.

\section{Turnbull Lectureship Honors Career of an Outstanding Researcher and Communicator}

The David Turnbull Lectureship recognizes the career of a scientist who has made outstanding contributions to understanding materials phenomena and properties through research, writing, and lecturing, as exemplified by the life work of David Turnbull. While honoring the accomplishments of the recipient, the Turnbull Lectureship is intended to sup- port and enrich the materials research community.

The recipient will give a technical lecture of broad appeal at a designated session of the 2000 MRS Fall Meeting. The Turnbull Lecturer will receive a $\$ 5,000$ honorarium and a citation plaque, along with travel expenses paid to enable the recipient to address MRS Sections and University Chapters, and/or participate in the production of a video version of the lecture.

\section{MRS Medal Recognizes Recent Discovery or Advancement in Materials Science}

The MRS Medal offers public and professional recognition of an exceptional recent achievement in materials research, which is expected to have a major impact on the progress of any materials-related field.

The award consists of a \$3,000 cash prize, an engraved and mounted medal, and a citation certificate.

\section{PREVIOUS AWARD RECIPIENTS}

\section{Von Hippel Award}

Arthur R. Von Hippel, 1977

Massachusetts Institute of Technology

William O. Baker, 1978 AT\&T Bell Laboratories

David Turnbull, 1979

Harvard University

W. Conyers Herring, 1980 Stanford University

James W. Mayer, 1981

Cornell University

Clarence M. Zener, 1982

Carnegie Mellon University

Sir Peter B. Hirsch, 1983

University of Oxford

Walter L. Brown, 1984

AT\&T Bell Laboratories

John W. Cahn, 1985

National Bureau of Standards

Minko Balkanski, 1986

Universite Pierre et Marie Curie

Sir Charles Frank, 1987

University of Bristol

Jacques Friedel, 1988

Universite de Paris-Sud
John B. Goodenough, 1989

University of Texas-Austin

Robert W. Balluffi, 1990

Massachusetts Institute of Technology

Theodore H. Geballe, 1991

Stanford University

Michael F. Ashby, 1992

Cambridge University

Frederick Seitz, 1993

The Rockefeller University

Alfred Y. Cho, 1994

AT\&T Bell Laboratories

William W. Mullins, 1995

Carnegie Mellon University

Sir Alan H. Cottrell, 1996

Cambridge University

Gabor A. Somorjai, 1997

University of California-Berkeley

Larry L. Hench, 1998

Imperial College

Richard S. Stein, 1999

University of Massachusetts

David Turnbull Lectureship

Thomas R. Anthony, 1992

General Electric Company
Morris Cohen, 1993

Massachusetts Institute of Technology

Arthur S. Nowick, 1994

Columbia University

Didier R. de Fontaine, 1995

University of California-Berkeley

Robert E. Newnham, 1996

Pennsylvania State University

Merton C. Flemings, 1997

Massachusetts Institute of Technology

H. Eugene Stanley, 1998

Boston University

Joseph E. Greene, 1999

University of Illinois

\section{MRS Medalists}

Arthur J. Freeman, 1990

Northwestern University

Duward F. Shriver, 1990

Northwestern University

Bernard S. Meyerson, 1991

IBM

Shigeyuki Sōmiya, 1991

Nishi Tokyo University

L. Eric Cross, 1992

The Pennsylvania State University
Stephen J. Pennycook, 1992

Oak Ridge National Laboratory

Wolfgang Krätschmer, 1993

Max-Planck Institute für Kernphysik

Donald R. Huffman, 1993

University of Arizona

Max G. Lagally, 1994

University of Wisconsin-Madison

Kenneth S. Suslick, 1994

University of Illinois-

Urbana-Champaign

Federico Capasso, 1995

AT\&T Bell Laboratories

Rudolf M. Tromp, 1995

IBM T.J. Watson Research Center

Jerry D. Tersoff, 1996

IBM T.J. Watson Research Center

Shuji Nakamura, 1997

Nichia Chemical Industries Ltd.

William L. Johnson, 1998

California Institute

of Technology

M. George Craford, 1999

Hewlett Packard

Stephen Forrest, 1999

Princeton University 